\title{
Beyond the Tease: Exploring Men's Constructions of Paying for Sex in South Africa
}

\author{
Ida Wepener, Despina Learmonth, Kirsten Leigh McLeod, Zakiya Chikte \\ University of Cape Town, Cape Town, South Africa
}

\begin{abstract}
Sex work in South Africa is poorly understood. Sex work and paying for sex are still considered illegal in South Africa. Research focus thus far has been on sex workers and their experiences. There exists a paucity of research literature on the perceptions of the client. This research focused on how South African men construct paying for sex. Semi-structured interviews were conducted to explore male clients' experiences of paying for sex. Through thematic analysis various themes emerged. Three main themes were identified: justifications, motivations, and deterrents. Our findings offer insight into South African heterosexual male clients' constructions of paying for sex. By gaining insight into the clients' constructed perceptions of paying for sex, we begin to understand the demand factor in sex work. Further research into the demand of male clients may deepen our understanding of the nature and consequences of sex work. This has the potential to impact legislation around sex work and aid in their construction of aspects of gender and sexuality.
\end{abstract}

Keywords: sex work, South Africa, social constructionism, masculinities, client, HIV (human immunodeficiency virus), AIDS

\section{Introduction}

The sex industry is a diverse and rapidly expanding business. The media often reports on the sensational aspects of sex work, such as illegal human trafficking networks, the spread of HIV (human immunodeficiency virus), and the use of illegal substances in the sex trade, whilst neglecting detailed commentary on the individuals who purchase sex: partners, friends, and community members (Willman \& Levy, 2010).

There is a significant amount of data about female sex workers, including empowering strategies and HIV/AIDS prevention strategies (Egan \& Frank, 2005; Willman \& Levy, 2010; Yen, 2008). However, less than $1 \%$ of studies around sex work include data about the male clients involved. This may be because sex work is inherently entrenched in gender and class discourses, and male clients' demand for sex work is often normalized (Perkins, 1991). Dominant discourse presents men as biologically primed to have sex with as many partners as possible (Marttila, 2008; Monto \& Julka, 2009; Peracca, Knodel, \& Seangtienchai, 1998; Raymond, 2003). As a hugely under-researched topic, exploratory qualitative research is necessary to investigate men's demand for sex work (Hobbs \& Wright, 2006). In South Africa particularly, where buying and selling sex is illegal, there is a paucity of research on how male clients construct buying sex. In order to gain a greater

Ida Wepener, BSocSc.(Hons.), Department of Psychology, University of Cape Town.

Despina Learmonth, DPsych., Department of Psychology, University of Cape Town.

Kirsten Leigh McLeod, BSocSc.(Hons.), Department of Psychology, University of Cape Town.

Zakiya Chikte, BSocSc.(Hons.), Department of Psychology, University of Cape Town. 
understanding of the demand factor in sex work, this research shifts the focus to the male clients, who are a vital feature of this social landscape (Erickson \& Tewksbury, 2000). Only through deepening understanding about the way in which male clients construct paying for sex, can we begin to reshape current dominant discourse around sex work and actively contribute to the debates around the legalisation of sex work.

Understanding social constructions of paying for sex is only possible through cognisance of current socially constructed frameworks around sex and sex work.

\section{Feminist Frameworks Around Sex Work}

The feminist debate on sex work revolves around whether it constitutes a form of voluntary sexual labour or involuntary sexual objectification (Brents \& Hausbeck, 2010).

Sex work as voluntary sexual labour. There is an increase in the commercialization of sexual intimacy. Sexuality and eroticism have become central to the globalized capitalist leisure culture (Sanders, 2008); freedom of sexual expression is becoming more acceptable in many societies (Brents \& Hausbeck, 2010). Generally, sex work is not considered to be an acceptable career choice, but some view it as an occupation in which workers retain their body and sexuality as consumable and marketable goods (Brents \& Hausbeck, 2010).

Liberal feminists argue that the sex worker contracts out a certain type of labour (the capacity for sexual activity) for a certain time in exchange for money. Therefore, her body is her "tool" required to provide a service. Sex workers are considered to have the power to choose whether or not to sell their sex.

There are however, challenges that face this position. Whilst gender inequality is changing in the arena of sexuality, women are still structurally disadvantaged in the workplace and society at large (Brents \& Hausbeck, 2010). Certain researchers suggest that some women do not readily choose prostitution as a "profession” but rather comply with the limited options available to them because of their poor economic circumstances (Hernandez-Truyol \& Larson, 2006; Nandipha, 2012; Raymond, 2003).

Sex work as involuntary sexual objectification. Another common perception among both the general population and scholars is that sex work is inevitable and perhaps natural. According to Canadian sex researcher Gemme (1993), "People will always have sexual needs which can only be satisfied by a commercial exchange” (p. 235). Seen in this way, sex work becomes normalised. However, feminist scholars argue that there are a number of problems with this understanding. Firstly, it ignores the ways in which sexual "needs" and desires are structured and shaped by society, instead viewing them as entirely biological or natural (O’Connell Davidson, 2002). Secondly, placing men's needs as paramount in shaping sexual practices reinforces a sense of masculine entitlement to sexual access that places the needs of others as secondary and contributes to the exploitation of women (Outshoorn, 2004). And lastly, this understanding implies a particular definition of masculine sexuality as motivated by a desire for sexual release rather than intimacy, promiscuity rather than monogamy, and a basic need that must be met, rather than a desire that may or may not be fulfilled (Hernandez-Truyol \& Larson, 2006; Raymond, 2003).

\section{Social Constructions Around Paying for Sex}

There is evidence of an existing dominant discourse that purports men to be naturally more sexually active and in need of a variety of sexual experiences (Marttila, 2008). As a result of the way in which typical behaviours for men and women are constructed, men are often placed in charge of sexual relations (Peng, 2007). Due to patriarchal ideologies entrenched in South African culture, a dominant discourse of hegemonic 
masculinity is particularly prevalent (Morrell, Jewkes, \& Lindegger, 2012). Men are constructed as having a high sex drive, dominating the sexual interaction, always being available for, and needing, sex, and having physical urges that are out of their control (Schneider, Cockcroft, \& Hook, 2008). Women are often expected to provide men with sex and be submissive to the sexual needs of men (Campbell, 1995; Petersen, Bhana, \& McKay, 2005). These understandings imply a particular definition of masculine sexuality as motivated by a desire for sexual release rather than intimacy, promiscuity rather than monogamy, and a basic need that must be met rather than a desire that may or may not be fulfilled. Such a definition of masculine sexuality may actually contribute to the conditions that perpetuate sex work, as men may come to define sex work as a natural outcome of their intrinsic sex drive (Hernandez-Truyol \& Larson, 2006; Raymond, 2003). Visits to sex workers are often constructed as a normative social group activity, and although men are not forced into participating, the group may covertly coerce an individual into participating by creating an accepting normative setting (Yang, Latkin, Liu, Nelson, Wang, \& Luan, 2010). Often visits to sex workers are considered a bonding experience with friends, an opportunity for business networking or as a rite of passage into manhood where men can prove their sexual adequacy to their peers (Peng, 2007; Yen, 2008). Male sexuality is viewed as something men have no control over. Succumbing to a constant need to satisfy strong sexual urges is seen as an inherent part of being a man (Morrison, 2006; Peng, 2007; Peracca et al., 1998; Yen, 2008).

In the literature, prostitution as a commodity refers to sex work as purely being about economic exchange, thus eliminating much of the intimate experience gained from sex (Monto \& Julka, 2009). This is referred to as unilateral pleasure, where clients do not have the time or desire to form conventional sexual relationships (Peng, 2007). In interviews with Finnish sex buyers, men spoke about buying sex as if it was any other market activity (Marttila, 2008). Several studies have found that men consider commercial sex work as a social networking tool (Peng, 2007; Raymond, 2003; Yang et al., 2010), often treating business partners to commercial sexual services in order to gain their support for economic endeavours (Peng, 2007; Raymond, 2003).

The appeal of a non-emotional and non-committed relationship and the desire for sex with a variety of different women are motivators for some men to seek commercial sex. Men appear to be attracted to the temporal relationship available through commercial sex because of the lack of emotional attachment. Men's fantasies around sex work often involve encountering a sexually advanced and experienced woman, who is willing to perform sexual acts not permissible with their wives or steady partners (Månsson, 2006; Monto \& Julka, 2009; Perkins, 1999).

More recent research reports that clients seek immediate control over sexual practices. Some clients argue that they spend a lot of money on obtaining the service; therefore, they expect variety in women and sexual practices. The greatest benefit according to some clients is that they do not have to be considerate of sex workers' feelings or needs. Clients see it as way of fulfilling sexual needs and fantasies that are not fulfilled by intimate partners. As a result of the dominant discourse around sex work, men have the power to choose, dismiss, and demand a woman to perform sexual acts as long as there is an economic exchange (Monto \& Julka, 2009).

Contradictory to the abovementioned motivations, some men seek out the services of sex workers in order to have a "girlfriend experience". This occurs when a woman acts as affectionate and excited in the exchange as she would in a consensual romantic relationship (Holt \& Blevins, 2007). Clients in Australia rated the sex worker experience higher when the sex worker made the client feel special (Holt \& Blevins, 2007). Some men also seemed to enjoy pleasuring a sex worker as it "validated" their masculinity through confirming their prowess as a lover (Sanders, 2008). 
In addition to the "girlfriend experience", there may be a cathartic element to relations with a sex worker as sex workers can provide a containing space where they listen to the client's problems, and offer emotional support (Perkins, 1999; Sanders, 2008). Peng (2007) explains how many clients fall in love with sex workers as they often fulfil romantic fantasies. In such instances, sex workers are affectionate, caring and appear to be reluctant for the client to leave (Peng, 2007). The practices between the client and sex worker are similar to those of typical romantic relationships: They go out on dates, chat, kiss, perform oral sex on each other and often fall asleep next to each other (Peng, 2007). Some clients visit the same sex worker for years, mimicking a monogamous relationship. Many clients consider sex workers to be their friends who they can trust and lean on emotionally (Peng, 2007; Perkins, 1999; Sanders, 2008).

In order to understand the mechanisms within sex work, it is essential to look at how client's demands may shape the profession as a whole. Without male clients' demand for paid sex, the profession would not exist (Martilla, 2008; Yen, 2008).

\section{Method and Design}

The research took on a feminist position while focusing on the social constructions around sex work and paying for sex work (Scheneider et al., 2008).

A sample of seven men was recruited using the "snowball" technique (see Table 1 for demographic data). Data were collected using semi-structured interviews. Participants were interviewed at times and in settings that suited them, in the hope that they would feel more comfortable and open to discussing their experiences. The interviews begun with a "grand tour question" (Corbin \& Morris, 2003). This allowed participants to tell their story from their own experiences.

Thematic analysis was used to analyse the data generated by this research. Thematic analysis provides a theoretically flexible way for themes within a data-set to be identified, organised, analysed, and reported (Braun \& Clarke, 2006). Thematic analysis is also compatible with a social constructionist approach: sensitive to the underlying meaning of what participants say (Parker, 2005). Three researchers analysed the data in order to reduce the bias of a single researcher's position.

Table 1

Demographic Information of Participants

\begin{tabular}{lllllll}
\hline Name & Province & Race & Age & Occupation & Relationship status & Previously married \\
\hline Bob & Gauteng & Black & 23 & Student & In a relationship & No \\
Derrick & Gauteng & White & 30 & Retail & Single & No \\
Frank & Western Cape & White & 36 & Optometrist & Single & No \\
Shawn & Western Cape & White & 35 & Construction & Complicated & Yes \\
Terrence & Western Cape & White & 31 & IT & Single & No \\
Tim & Western Cape & White & 32 & Property & Single & No \\
Wayne & Gauteng & Indian & 31 & Retail & Single & No \\
\hline
\end{tabular}

\section{Ethical Considerations}

This research was approved by the Department of Psychology's Ethics Committee at the University of Cape Town, and adhered to the University of Cape Town's guidelines for research with human subjects. Additionally, the research met the ethical requirements specified by the Research Ethics Department of the Department of Psychology. 


\section{Analysis and Discussion}

The three main themes identified were motivations, justifications, and deterrents in paying for sexual services (particularly sexual services for which the legal remuneration of would be considered illegal in South Africa, for example, oral sex or sexual intercourse).

\section{Justifications in Paying for Sex Work}

The most prominent theme that emerged from the analysis was justifications; through which the male clients constructed their behaviour as being "reasonable". Throughout the interviews, participants constantly represented their experiences as reasonable by normalising the act of paying for sex. Sub-themes relating to the justifications of paying for sexual services included: Madonna/whore complex, passivity, peers, intoxication, context, and commodity.

Madonna/whore complex. Throughout the interviews, participants referred to sex workers or women whom they considered to be promiscuous as "girls" or "chicks", whilst referring to women they would consider an intimate relationship with as "women". Tim explains that "(he) went home and the girl (went) with him", whereas Shawn says that "if (he) meets a woman with higher morals, then it's for (him)". Participants appeared to make distinctions between the dualistic "types" of women and ascribed specific roles and characteristics to each group respectively.

Participants often compared "one night stands" with buying sex. Terence states: "I mean there is the argument, what really is the difference between a one night stand and uhm, a prostitute, like there isn't much of a difference".

They seemed to desire promiscuous women, and were not against spontaneous sexual interactions, but viewed these women in a negative light, and did not see them as dating or marriage material. Shawn explains:

There's the other side where you're always looking for that nice girl, the one you can be in a relationship with and then the thing is if she makes it too easy to sleep with straight off then you kind of loose that respect, you wanna work hard... if I meet a woman who has higher morals... I view her as relationship material.

Participants were often demeaning towards women who were considered promiscuous or who were working within the sex industry. Participants described these women as having "daddy problems", a "lack of self-respect and self-esteem” and "self-destructive tendencies". Tim explained in detail that "... they lose a touch of their femininity... must be a lot of demons going through their heads". This suggests that a woman considered promiscuous becomes less of a woman and is considered to be deviant and abnormal. This is in accordance with literature around constructions of masculinity and femininity: Men are typically thought to be driven by biological urges and are allowed to actively pursue and initiate sexual activities, whilst women are expected to be passive and relatively disinterested in sex (Schneider et al., 2008; Marttila, 2008). Women acting contrary to these dominant constructions are often marginalised and viewed as transgressive. Many participants believed common myths around sex work, and agreed that most sex workers choose to do the work they do; thus they do not view them as victims of circumstance. Terrence stated that “... (he does not) see them as victims... it's an opportunity to make a shit load of money... no one is putting a gun against her head and tell her she must do that".

Passivity. Participants often represented themselves as being passive agents within the context of buying sex: Sex workers took the lead in the interaction by approaching them, as Derrick explained "(he) was approached by a Thai girl and (he) was like, okay, I may as well try this thing”. It seems that male clients 
suggest passivity as a means of justifying their choice to buy sex, as Frank explains “... Beautiful women throwing themselves at you, you just end up doing it”. This ties in with the dominant construction of men as always being available for and needing sex (Schneider et al., 2008). As a result, when sex is offered to them, it is represented as almost impossible for them to resist.

Peers. The majority of participants reported being part of a group when they paid for sexual services. Recounting their experiences with sex workers, they emphasized that they were out with friends and participated in buying sex as part of a group experience or due to peer pressure. Terrence, in response to a question about attending a strip club alone, responded saying "No, I don’t think I would... the thing with a strip club, it's got a lot more to do with the party". Going to a strip club or brothel was viewed as normative within a group of male friends, as a "partying” and "bonding” experience. Some participants felt more pressure to fit in with their male friends' escapades. Bob told us about his experience with a particular friend of his: "Every time I go out with this guy... he knows exactly where to take me, and I'm not just gonna stay in the car when this guy...gets business handled". It seems participants do not want to feel "left out" or be seen as "less of a man" within their peer group. On rare occasions participants sought sex services on their own, although they were usually referred by a friend to "tried-and-tested" services. In example, Wayne reported "A friend of (his) told (him) he used to look at 'sex rater”".

Intoxication. Participants communicated that being under the influence of alcohol or illegal substances, such as marijuana, cocaine, and acid influenced whether they bought sex or not. Being under the influence of a substance made the act of paying for sex easier and more "fun" as they felt less inhibited. A few participants also referred to themselves as a "different person" when in these situations. According to Shawn: "It doesn't feel real because I was so drunk". Intoxication justified the act of paying for sex as a feature of partying which allowed the participants to be "wild and crazy" and "let off steam" within the safety of a male peer group. As Tim described: "When you're under the influence of alcohol or drugs I think you can do anything! So paying for sex is much easier that way, and then it’s more fun! You don't think about anything, you just do it!”.

Context. Participants also indicated that the context in which they found themselves had a considerable influence on whether they would pay for sex. Being in a context where the sale of the female body already exists, makes committing the illegal act of buying sex so much easier. Frank states: "What motivates a guy as well is when they see a whole lot of naked women”. Terence echoes this:

Cause males are very visual creatures, like we love to see naked women all the time and its nice when there's a naked women that you don't know from a bar of soap bumping and grinding up on you, and getting youaroused and it is like, it is like all about the party, you know doing body shots off them, drinking, going wild...

Thus some participants frame sex work as normative within particular settings, such as strip clubs, because these places offer a different context from those of their daily lives. These are "masculine spaces", where men are allowed to be men and engage in behaviours that may be frowned upon in social settings, such as drinking, smoking, being "rowdy" and vulgar (Katsulis, 2010).

Commodity. Participants perceived sex work as a "normal" form of exchange in a capitalist society, a legitimate profession that is in demand. Common myths about sex workers include that women are sex workers out of free will, earn a decent income, and enjoy their work (Yen, 2008). Derrick explains: "As long as you have a cash crazy society you'll have some prostitution", and Tim: "It's a massive market... it's available... so every male will do it once or twice in their life time”. Bob’s statement that "Sex and money are the two biggest 
sins ever, they interlink so well” illustrates how male clients view sex as a legitimate commodity. There seems to be the implication that if you have money you afford the right to buy sex. Bob recounts his friend asking "Why (anyone) would need a girlfriend if you got like, 30 bucks in your pocket". This emphasizes the idea that the female body and sex can be bought easily without any emotional investment. Shawn describes the act of paying for sex as “... a business exchange”.

Participants legitimise paying for sex by suggesting that even within the dating context where their intention is to pursue a sexual encounter men have to make some form of financial investment, as Terrence states: "Sex is really not for free". In South Africa males are still considered to be the primary earners (Schneider et al. 2008), and are usually expected to pay for much of a dating couples' mutual entertainment. Bob explained in detail: “... dating is kind a more expensive, you know if you take a chick out... you have a good time... but your wallet ain't”. The above statement illustrates participants may regard women as a commodity, and this may justify and normalize the act of directly paying for sexual services. Bhana, Morrell, Hearn, and Moletsane (2007) pointed out some of the dangers of individuals affirming patriarchal heterosexual gender identities. For example, if young women invest heavily in essentialist femininity, they can make themselves vulnerable by using their sex as a means of attending to material needs. Similarly, research with an Australian sample found that men viewed sex as a commodity and women as the gatekeepers of sex. Women would only provide sex once the men have fulfilled certain practices (Mooney-Somers \& Ussher, 2010).

\section{Motivations to Pay for Sex}

Motivations are factors that drive male clients to seek out sexual services. The sub themes identified under motivations were: "girlfriend experience", fulfilment, ease, and fantasy.

“Girlfriend experience". The "girlfriend experience" involved seeking out a more intimate experience with a sex worker, including verbal and physical affection, such as talking and kissing (Katsulis, 2010). The majority of participants felt a strong desire to be able to connect or feel a sense of intimacy with a woman, and therefore preferred encounters with sex workers where this role had the potential to be fulfilled. Derrick makes this point quite clear, as he explains: “... just like to speak to the woman and get to know where she was in life”. Similarly, Shawn described one of his most memorable encounters: "We sat talking for about 20minutes, she got undressed, and undressed me, and we started kissing and stuff like that... very easy". Paid sexual experiences may represent features of traditional romantic relationships and a longing for a real and reciprocal erotic connection (Katsulis, 2010). Tim states: "I just kept going there... identify one particular person, ... and then it's easier to take them home with you, because you know them better”. Consistent with previous research, participants display a longing for the presence of psychological and emotional aspects within the relationship (Schneider et al., 2008).

Fulfilment. All of the participants believed that some of the main reasons why (other) men pay for sex have to do with fulfilment of sexual needs. Frank indicated that some men may get "bored" and "need a variety of women", or "are not getting at home". Bob argued that what persuaded him "a bit more" to pay for sex was the lack of oral sex that he received from his partner(s): “... the past weeks blowjobs weren't amazing ..., so I'll settle for a blowjob... I'll spoil myself”. There seems to be a consensus in some research that men have a high sex drive, and if this is not fulfilled by an intimate partner, they may seek out sex workers to fulfil their sexual needs. Sex workers are often said to satisfy desires that are not fulfilled by an intimate partner, especially amongst married men (Månsson, 2006; Peng, 2007; Perkins, 1999; Sanders, 2008). Similar to research findings 
by Mooney-Sommers and Ussher (2010), male participants repeatedly suggested that they needed to be constantly pleasured, and always needed more sex than what they were currently getting.

Ease. One of the participants described paying for sex as easier than going out to a bar and "picking up" a woman. They also did not have to deal with the emotional commitment women often expect after intimate sexual relations. Participants sometimes desired sex which was solely for the purpose of sexual pleasure and free of emotional demands (Joseph \& Black, 2012). According to Shawn "Often you don’t want the schlep of dealing with the aftermath". Research has found that male clients often seek out sex work because it is perceived as easier than the emotional entanglement and demands of a romantic relationship (Peng, 2007; Pitts, Smith, Gierson, O’Brein, \& Misson, 2004). Participants regarded the process of having to flirt with a woman prior to having sex as too much effort, therefore it was easier for them to pay a sex worker for sex. Derrick explains: “...You know you go out and there is a whole like mating ritual involved, so it can be exhausting to you". This may also be due to the fear of rejection by a potential partner prompting reluctance to pursue traditional romantic relationships.

Fantasy. Several of our participants described sex workers as representative of women who only exist in their fantasies. Shawn describes a memorable sex worker as: “... very very beautiful woman”. Frank also describes sex workers in Prague as: “... Unbelievably beautiful... I don’t think you would ever see a woman that nice in your life". Participants often described sex workers as being of a calibre of physical attractiveness which they could not hope to attain in their usual daily social settings. Participants were willing to pay for women that were capable of fulfilling their fantasies. Terrence explains: “... it’s like a fantasy world really... like in the real world it's not that easy to stare at a woman and she comes and sits on your lap ...”. When participants were asked why they think other men would pay for sex, most of them included as reasons, fantasies that are not fulfilled by intimate partners, as well as the need to engage with sexual fetishes.

The above social constructions of why men are motivated to pay for sex are socially constructed and therefore seem to legitimize male clients' motivations in seeking out sexual services, framing paying for sex as a conventional and acceptable male practice (Katsulis, 2010).

\section{Deterrents in Paying for Sex}

Deterrents towards paying for sex can be defined as factors that discourage the male client from returning to sex workers and using certain types of sex workers. Subthemes included: stigma, fear of disease, discomfort and guilt, and trafficking.

Stigma. Participants made it very clear that they believed that paying for sex is not socially acceptable. Paying for sex is a "hush hush thing", to the extent that participants do not even discuss their experiences with sex workers amongst friends and family. Bob explains: "It's (paying for sex) not so common... still taboo ... you still won't hear it from people”. Participants are aware of social stigma and do not want people to know that they have participated in the sex industry, as Frank says: "A lot of people would look at you and be like, how can you do that?". Participants believe that if people were to find out about their "in discrepancies” it would influence how people perceive them, as Wayne reflects: “... it brings down your status level as a male” as well as Terrence: "The fact that you had to pay for sex, kindademasculates me... it doesn't make you a man...”. Here it appears that having to pay for sex is perceived as emasculating. This contradicts the social constructions around buying sex and enhanced masculinity highlighted in the "peers" theme. Our participants felt that paying for sex can be seen in part as a "failure" to be a "real man". Masculine identity is closely linked 
to sexuality and sexual practice, so this perceived sexual failure can challenge a man's sense of self and his masculinity (Schneider et al., 2008).

In line with the sub-theme of stigma, participants spoke of the "normal client" as a deviant member of society, different to themselves. They disassociated themselves from the average client, and appeared to construct a separate identity when purchasing sex. Participants argued that they became "different people" when they were under the influence of substances and with their peers, blaming sex workers for "throwing" themselves at male clients. These constructions of paying for sex can lead men to be caught between experiencing sex as a source of pleasure and power, reinforcing their masculine identity, whilst simultaneously feeling that sexual favour may threaten their masculinity and stigmatize them (Schneider et al., 2008).

The participants were also concerned about how stigma around purchasing sex may affect their ability to date. They believe that if a "regular" woman were to find out, it would ruin their chances of pursuing a traditional romantic relationship, as Tim says: "It's not something you broadcast, you still want to have sex with regular women". Shawn believes that sex work is taboo and would not ever tell a potential partner that he has paid for sexual services previously as he believes it to be “... a sure way to end a relationship”. The way sex work is constructed in South Africa appears to discourage male clients from being open about their sexual experiences with sex workers. This stigma may be reinforced by the fact that paying for sex is a criminal activity in South Africa. Interestingly, none of the participants mentioned illegality as a deterrent, perhaps illustrating how paying for sex is still widely tolerated in South Africa. Participants wanted to keep their involvement with the sex industry as reticent as possible. International research supports the notion that male clients of sex workers are part of a "hidden sample" and are willing to go to great lengths to keep their involvement in the sex industry a secret (Monto \& Julka, 2009; Peng, 2007; Sacramento, 2011).

Fear of disease. The majority of participants raised concern about STIs (sexually transmitted infections), especially when considering South African sex workers. This was not a recurring theme in reviewed international literature, where male clients often did not use protection and seemed unperturbed by the dangers of unprotected sexual activities (Goldenberg, Strathdee, Gallardo, Rhodes, Wagner, \& Patterson, 2011; Yang et al., 2010). Fear of disease may be more prevalent in South Africa, because South Africa has one of the highest levels of HIV infection in the world, an estimated 5.2 million people (approximately 12\%), making it likely that South African participants may be more mindful of contracting the virus (Morrell, Jewkes, \& Lindegger, 2012). Studies on the prevalence rates of HIV in South Africa-based sex workers report rates of between 34\% and 59\% (Dunkle, Beksinska, Rees, Ballard, Htun, \& Wilson, 2005; Parry, Petersen, Carney, Dewing, \& Needle, 2008; Van Loggerenberg et al., 2008). Most of our participants were very concerned about contracting STI's and reported to have always used condoms. Frank noted: “... You can get STD’s from even with a condom on”.

However, some participants were surprisingly naïve when it came to their views on the "cleanliness" of Eastern European sex workers; Shawn accounts: "I just think there (in Prague) it's a lot cleaner". Frank highlights this discrepancy between perceived "quality" and "cleanliness" of sex workers locally and abroad quite explicitly:

... Majority of the girls here (South Africa) are non-white... They are not very nice girls... I mean, R800, anybody can pay for that so you don't know what's before you... But overseas, a Russian girl, Eastern European girl who is R15000, she obviously doesn't do it that often.

The belief around economic exclusivity in access to certain sex workers, and the ideas on occurrence of 
STI's, seem to be strongly linked to perceptions of class, and in the South African context, race. In South Africa, HIV is commonly believed to be a predominantly black person's disease (Leclerc-Madlala, Simbayi, \& Cloet, 2009) and black women are still the most economically disadvantaged group (UNESCO 2008). As such, white women belonging to a higher SES (socio-economic status) group may be considered "cleaner" and more "desirable". Consideration of the intersecting influences of race, class, and gender on sex work in South Africa (Kempadoo, 2001; Hakala, Keller, \& Learmonth, 2012) is important in deepening our understanding of how these factors influence paying for sex.

Discomfort and guilt. It was apparent that majority of the participants felt uneasy about the act of paying for sexual services. Participants expressed this discomfort with terms such as "awkward”, "weird”, "strange", "sick", and "dodgy". Shawn explains that "It's not like we high five each other when we get out, we know that we've been misbehaving”. Participants expressed varying degrees of distress and discomfort around buying sex, as Frank states: "You've got the guilt, you feel like you've done something wrong” and Derrick explains that he "didn’t actually want to look at her, just because it was such an awkward situation”. Although participants express their experiences as a deviant act, several studies show that sex workers' clientele are ordinary, heterogeneous citizens from numerous nationalities, cultures, religious, socio economic backgrounds, and marital statuses (Mansonn, 2006; Monto \& Julka, 2009; Morrison, 2006; Peng, 2007; Perkins, 1999; Yang et al., 2010). This may be attributed to the stigma around sex work in South Africa, although it is possible that some men may feel that paying for sex is unethical which may cause feelings of distress. Possibly because of these constructions of what a "real man" is, participants felt "bad" or "guilty" about the act of paying for sex, so much so that two of the participants said that they would never pay for sex again. However, even though all the participants expressed discomfort and guilt, most said that given "appropriate" circumstances, they would strongly consider making use of sexual services again.

Trafficking. Some participants emphasized that they were aware that while some women may choose to sell sex, there are those who are trafficked and work under a "pimp". These participants would not want to make use of sexual services by a sex worker who has potentially been trafficked as they believe they are more prone to "exploitation" and feel "sorry" for them. Derrick explained that he knew a few women who have worked as exotic dancers and have "tried out" engaging in sex work and "really regretted the decision afterwards". Wayne felt that he "would... advise against it because of the dangers". These participants indicated that they were pro legalization of sex work in South Africa. According to Bob, "If you want to be a prostitute we should allow that... and have some sort of security guard to help you". Wayne similarly commented that "(he) think(s) it should be legalized and there should be education surrounding it... because, like guys end up raping prostitutes”. These participants came across as protective over those sex workers they perceived to be coerced or trafficked, and were not in support of these "types" of sex workers.

\section{Research Limitations}

Qualitative research tends to be considered limited in that hypothesis testing is not possible, results are less generalizable, and it can be difficult to establish reliability and validity (Braun \& Clarke, 2006).

Sample sizes are also often smaller in qualitative research. The size and nature of the sample can be considered as a limitation (see Table 1). Hobbs and Wright (2006) deemed the approach of snowballing as a personal affair, where some will be included and others excluded, as in an everyday friendship group. The disadvantage of the sampling technique of snowballing is that it can result in attracting the same type of 
participant, in terms of their demographic characteristics and personality. All participants were in a middle- to higher SES class. Their views on sexuality may also be considered liberal and not necessarily representative of the generally conservative construction of sexuality in South Africa.

As research is embedded within power relations, it is important for researchers to be able to reflect on their connectedness with participants, and to explore how building the relationship may have led to the specific data at hand. Reflection on the similarities and differences between the self and participants is vital (Andrews, Squire, \& Tamboukou, 2008). As researchers, we were mindful of the fact that the male participants may have been reluctant to share their accounts with us in detail and that concealment may have been an issue.

\section{Conclusion}

This research aimed to explore how South African men talk about their experiences of paying for sex work. The three main themes identified were: justifications, motivations, and deterrents. This study has contributed to addressing the gap in research on sex work in several ways. It is evident that men who seek out sexual services in South Africa share common motivations with male clients in other parts of the world, such as the "girlfriend experience”, ease, and fulfilment and fantasy (Katsulis, 2010; Månsson, 2006; Peng, 2007; Pitts, Smith, Gierson, O’Brein, \& Misson, 2004; Perkins, 1999; Sanders, 2008; Schneider et al., 2008). These motives may be considered "normal" and used as evidence for the legalization of sex work (Hernandez-Truyol \& Larson, 2006; Raymond, 2003). Those in favour of legalization argue that legalization will lead to better control of the sex industry and sex trafficking, leading to greater protection and better health outcomes for sex workers (Hernandez-Truyol \& Larson, 2006; Yen, 2008). The concerns around the trafficking and exploitation of sex workers in South Africa by some participants are better related to feminist discourse around sex work as involuntary (Hernandez-Truyol \& Larson, 2006; O’Connell Davidson, 2002; Outshoorn, 2004). Raymond (2003) believed that legalizing sex work will further entrench the construction of women as commodities and sex work as harmless and fun.

In addition to international findings, justifications and deterrents were identified. These themes and their sub-themes highlighted South Africa's conservative and patriarchal construction of sex and sexuality (Morrell, Jewkes, \& Lindegger, 2012; Schneider et al., 2008), as well as the disjunction experienced in constructions of masculinity and paying for sex. The participants were also very conscious of the possibility of contracting STI's and aware of the necessity of protection through the use of condoms; as opposed to their international male counterparts who appeared to be less concerned about STI's (Campbell, 1995; Peracca et al., 1998; Raymond, 2003). One could view South African men's awareness of STI's and the need for condoms in a positive light as this behaviour ensures better physical health outcomes for both the client and the sex worker.

Our findings offer some insight into heterosexual male clients' constructions of paying for sex. The way in which participants construct seeking sex work seems to be entrenched in dominant constructions of gender and sexuality in South Africa. Sex work is a complicated phenomenon with a range of outcomes for all agents involved. Further research into male clients' demand for sex work can deepen our understanding of the nature and consequences of sex work. This has the potential to contribute to the on-going debate around the decriminalisation of sex work in South Africa, and thereby impact current and future sex work legislation.

\section{References}

Andrews, M., Squire, C., \& Tamboukou, M. (2008). Doing narrative research. London: SAGE Publications. 
Bhana, D., Morrell, R., Hearn, J., \& Moletsane, R. (2007). Power and identity: An introduction to sexualities in South Africa. Sexualities, 10, 131-139.

Braun, V., \& Clarke, V. (2006). Using thematic analysis in psychology. Qualitative Research in Psychology, 3, 77-101.

Brents, B. G., \& Hausbeck, K. (2010). Sex work now: What the blurring of boundaries around the sex industry means for sex work, research and activism. In M. H. Ditmore, A. Levy, \& A.Willman (Eds.), Sex work matters: Exploring money, power and intimacy in the sex industry (pp. 9-22). London/New York: Zed Books.

Campbell, C. A. (1995). Male gender roles and sexuality: Implications for women's AIDS risk and prevention. Social Science \& Medicine, 41, 197-210.

Corbin, J., \& Morris, J. M. (2003). The unstructured interactive interview: Issues of reciprocity and risks when dealing with sensitive topics. Qualitative Inquiry, 9, 335-354.

Dunkle, K. L., Beksinska, M. E., Rees, V. H., Ballard, R. C., Htun, Y., \& Wilson, M. L. (2005). Risk factors for HIV infection among sex workers in Johannesburg, South Africa. International Journal of STD \& AIDS, 16, 256-261.

Egan, R. D., \& Frank, K. (2005). Attempts at a feminist and interdisciplinary conversation about strip clubs. Deviant Behavior, 26, 297-320.

Erickson, D. J., \& Tewksbury, R. (2000). The gentlemen in the club: A typology of strip club patrons. Deviant Behaviour, 21, 271-293.

Gemme, R. (1993). Prostitution: A legal, criminological, and sexological perspective. Canadian Journal of Human Sexuality, 2, 227-237.

Goldenberg, S. M., Strathdee, S. A., Gallardo, M., Rhodes, T., Wagner, K. D., \& Patterson, T. L. (2011). Over here, it’s just drugs, women and all the madness: The HIV risk environment of clients of female sex workers in Tijuana, Mexico. Social Science \& Medicine, 72, 1185-1192.

Hakala, S., Keller, M., \& Learmonth, D. (n. d.). “I can’t carry on like this”: A perspective on the gendered nature of barriers to exiting sex work in the African context (forth coming).

Hernandez-Truyol, B. E., \& Larson, J. E. (2006). Sexual labor and human rights. Columbia Human Rights Law Review, 37, 391-445.

Hobbs, D., \& Wright, R. (2006). Researching sex work: Dynamics, difficulties and decisions. The SAGE Handbook of Fieldwork, 5, 202-216.

Holt, T. J., \& Blevins, K. R. (2007). Examining sex work from the client's perspective: Assessing johns using on-line data. Deviant Behaviour, 28, 333-354.

Joseph, L. J., \& Black, P. (2012). “Who’s the man?” fragile masculinities, consumer masculinities, and the profiles of sex work clients. Men and Masculinities, 15, 486-506.

Katsulis, Y. (2010). "Living like a king”: Conspicuous consumption, virtual communities, and the construction of paid sexual encounters by US sex tourists. Men and Masculinities, 13, 210-230.

Kempadoo, K. (2001). Women of color and the global sex trade: Transnational feminist perspectives. Meridians, 1, $28-51$.

Leclerc-Madlala, S., Simbayi, L. C., \& Cloet, A. (2009). The sociocultural aspects of HIV/AIDS in South Africa. In P. Rohleder, S. C. Kalichman, \& L. Swartz (Eds.), HIV/AIDS in South Africa 25 Years (pp. 13-25). Berlin: Springer.

Månsson, S. A. (2006). Men’s demand for prostitutes. Sexologies, 15, 87-92.

Marttila, A. M. (2008). Desiring the other. Gender Technology and Development, 4, 12-31.

Monto, M. A., \& Julka, D. (2009).Conceiving sex as a commodity: A study of arrested customers of female street prostitutes. Western Criminology Review, 1, 1-14.

Mooney-Somers, J., \& Ussher, J. M. (2010). Sex as commodity: Single and partnered men’s subjectification as heterosexual men. Men and Maculinities, 12, 353-373.

Morrell, R., Jewkes, R., \& Lindegger, G. (2012). Hegemonic masculinity/masculinities in South Africa: Culture, power and gender politics. Men and Masculinities, 15, 11-30.

Morrison, L. (2006). “It's in the nature of men”: Women's perception of risk for HIV/AIDS in Chiang Mai. Culture, Health \& Sexuality, 8, 145-159.

Nandipha, K. (2012, April 21). Call to legalize sex work. Daily Dispatch. Retrieved July 17, 2012, from http://www.dispatch. co.za/call-to-legalise-prostitution/

O’Connell Davidson, J. (2002). The rights and wrongs of prostitution. Hypatia, 17, 84-98.

Outshoorn, J. (2004). The politics of prostitution: Women's movements, democratic states and the globalisation of sex commerce. England: Cambridge University Press. 
Parker, I. (2005). Qualitative psychology: Introducing radical research. London: Open University Press.

Parry, C., Petersen, P., \& Carney, T., Dewing, S., \& Needle, R. (2008). Rapid assessment of drug use and sexual HIV risk patterns among vulnerable drug using populations in Cape Town, Durban and Pretoria. South Africa Journal of Social Aspects of HIV/AIDS, 5, 113-119.

Peng, Y. (2007). Domination and difference in the discourses of Taiwanese Piao-ke. Men and Masculinities, Shih Hsin University Taiwan, 9, 315-336.

Peracca, S., Knodel, J., \& Seangtienchai, C. (1998). Can prostitutes marry? Thai attitudes toward female sex workers. Social Science Medical, 47, 255-267.

Perkins, R. (1999). “How much are you, love?” The customer in the Australian sex industry. Social Alternatives, 18, 38-47.

Petersen, I., Bhana, A., \& McKay, M. (2005). Sexual violence and youth in South Africa: The need for community-based prevention interventions. Child Abuse and Neglect, 29, 1233-1248.

Pitts, M. K., Smith, A. M. A., Gierson, J., O’Brein, M., \& Misson, S. (2004). Who pays for sex and why? An analysis of social and motivational factors associated with male clients of sex workers. Archives of Sexual Behavior, 33, 353-358.

Raymond, J. G. (2003). Ten reasons not to legalize prostitution and a legal response to the demand of sex work. Journal of Trauma Practice, 2, 315-322.

Sacramento, O. (2011). Liminal spaces: Reflections on the proxemia of cross-border demand for prostitution. Space and Culture, 14, 367-383.

Sanders, T. (2008). Male sexual scripts: Intimacy, sexuality and pleasure in the purchase of sex. Sociology, 3, 400-409.

Schneider, V., Cockcroft, K., \& Hook, D. (2008). A fallible phallus: A discourse analysis of male sexuality in a South African men's interest magazine. South African Journal of Psychology, 38, 136-151.

UNESCO. (2008). South African national report on the development and state of the art of adult learning and education. Retrieved January 3, 2013, from http://www.unesco.org/fileadmin/MULTIMEDIA/INSTITUTES/UIL/confintea/pdf/ National_Reports/Africa/Africa/South_Africa.pdf

Van Loggerenberg, F., Mlisana, K., Williamson, C., Auld, S. C., Morris, L., Abdool, K.,... Salim, S. (2008). Establishing a cohort at high risk of HIV infection in South Africa: Challenges and experiences of the CAPRISA 002 acute infection study. doi:10.1371/journal.pone.0001954

Willman, A., \& Levy, A. (2010). Introduction: Beyond the sex in sex work. In M. H. Ditmore, A. Levy, \& A. Willman (Eds.), Sex work matters: Exploring money, power and intimacy in the sex industry (pp. 1-6). London/New York: Zed Books.

Yang, C., Latkin, C. A., Liu, P., Nelson, K. E., Wang, C., \& Luan, R. (2010). A qualitative study on commercial sex behaviours among male clients in Sichuan Province, China. AIDS Care, 22, 46-252.

Yen, I. (2008). Of vice and men: A new approach to eradicating sex trafficking by reducing male demand through educational programs and abolitionist legislation. The Journal of Criminal Law \& Criminology, 2, 653-686. 